\title{
Invisible Disagreement: an Inverted Qualia Argument for Realism
}

\author{
Justin Donhauser
}

\begin{abstract}
Scientific realists argue that a good track record of multi-agent, and multiple method, validation of empirical claims is itself evidence that those claims, at least partially and approximately, reflect ways nature actually is independent of the ways we conceptualize it. Constructivists contend that successes in validating empirical claims only suffice to establish that our ways of modelling the world, our "constructions," are useful and adequate for beings like us. This essay presents a thought experiment in which beings like us intersubjectively validate claims about properties of particular things in nature under conditions in which those beings have profoundly different personal phenomenological experiences of those properties. I submit that the thought experiment scenario parallels our actual situation, and argue that this shows that successes in intersubjectively validating empirical claims are indeed enough to claim victory for the realist. More specifically, I champion a variation of realism that marries Ronald Giere's brand of 'perspectival realism' with Philip Kitcher's 'real realism,' and posits that causal relations between ourselves and properties instantiated in nature ground our references to the relevant properties even though our conceptions of them are perspective relative (or filtered through, and distorted by, a perspective).
\end{abstract}

\section{Keywords: Realism - Constructivism - Inverted Spectrum - Color Vision}

\section{INTRODUCTION}

Two sighted persons may each perceive the same patch of sky as being of different shades, as in the color swatches below, but both explicitly agree that that patch is the same shade of blue. For example, they might agree that that patch of sky is the exact same color as shade \#0064 of a particular brand of paint.
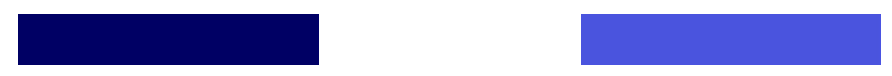

Although the degree of disparity in each of our subjective phenomenological content may not be as severe as in the above swatches-given biological contingencies and variability-this situation is certainly to some extent indicative of our own. ${ }^{1}$ This essay examines situations like this, what I will call 'invisible disagreement' situations, that can and do occur between perceiving beings like us. I will argue that the fact that 'invisible disagreements' occur breaks the alleged "tie between the

\footnotetext{
1 There is an enormous amount of neuroscience research establishing that phenomenal content can vary drastically across subjects perceiving the same things. Color-blindness and other color perception disorders serve as obvious, severe, examples. For instance, 'synesthesia' is a well-documented condition in which a brain activity abnormality can result in perceiving black and grey text (letters and numerals) in character-isomorphic colors-e.g. Q's may always appear red to someone with the condition; see Robertson \& Sagiv 2004 and Byrne \& Hilbert 2003 and the sources cited therein.

J. Donhauser

E-mail: jcdonhauser@gmail.com
} 
empiricist stance and the metaphysical stance"- the tie between scientific constructivism and realism (Psillos 2013, p. 35).

Constructivists see "realist affirmations as going beyond what the evidence demands" (Sober 2008 , p. 129). They hold that the only "reality" we are justified in claims to empirical knowledge about is our models of the natural world, on grounds that there is no evidence available to found the realist idea that our empirical claims are true to model-independent reality. This is the prevailing view in science and the philosophy thereof. In the popular science literature, Stephan Hawking defends constructivsm calling it "model-dependent realism" (see 2011, p. 45) and in the philosophy of science Bas van Frassen has defended the most mature formulation of it calling it "constructive empiricism" since the 1980's (see van Frassen 2002; 1989; 1980). And, historically, the view has been a dominant one in philosophy in general, since Kant dubbed it "empirical realism" in his famous synthesis of the views of Bishop Berkeley and David Hume (CPR A369-70).

In rebut of the received constructivist stance, I will argue that 'invisible disagreements' are most probably a persistent feature of our situation and can only be sufficiently accounted for with a realist epistemology. Specifically, I will contend that the occurrence of 'invisible disagreements' can only be accounted for with an epistemology according to which multiple perceiving agents intersubjectively validate empirical claims by accurately pointing to properties instantiated in modelindependent reality. I will defend this conclusion by laying out an intuition-pump style thought experiment that highlights the implications of 'invisible disagreements' and serves to show why realism prevails over constructivism.

As a first pass characterization, an 'invisible disagreement' is essentially a situation like the one described above, in which there is a lack of intersubjective disagreement about qualities attributed to things in the world even though there are intrasubjective (perceiver-isomorphic) disparities - that is, disagreement in the phenomenological content of the agents validating claims about the salient qualities. The thought experiment presented below (in \$5) expands upon this basic situation, and thereby illustrates how a community of perceiving beings like us can communicate about and collectively navigate the world quite well without such phenomenological disparities ever becoming the source of explicit disagreements about empirical claims. In so doing, it provides insights into the way in which we interface with perceiver-independent reality and into the grounds of agreement and disagreement about empirical claims. Most notably, it will come to light that a realist epistemology can account for invisible disagreements, and that a constructivist one cannot. The presented thought experiment also bears implications for how realism can be most reasonably formulated, and I will argue that the experiment suggests that a specific interpretation of Ronald Giere's (2006 and 1999) 'perspectival realism' beats out the prevailing constructivist stance. ${ }^{2}$ Accordingly, I will champion a variation of realism that marries Giere's brand of 'perspectival realism' with Philip Kitcher's 'real realism,' and posits that causal connections between ourselves and properties instantiated in nature ground our references to the relevant properties even though our conceptions of them are perspective relative (or filtered through, and distorted by, a perspective).

\section{The Crux of the Realist/Constructivist Debate}

Constructivists and realists mostly agree that the ways we represent and communicate about the world are instrumentally productive and that it is valuable, and therefore rational, to believe in the

\footnotetext{
2 The discussion herein also bears significant implications for current debates in action theory that are outside the scope of this work; see Bradley 2011, Ward et al 2011, Noë 2004, and Pettit 2003.
} 
entities we posit to make sense of natural phenomena. ${ }^{3}$ They can also agree that the seemingly robustly existent, "worldly," entities of everyday life (e.g. tables and chairs) and those studied in the natural sciences (e.g. organisms and atoms) exist in the sense that there is something out in nature with which we causally interact (see Sider 2012, p. 165). As Philip Kitcher says:

Our purchase on the idea that some objects are independent of some of us (although observed by others) suffices to make intelligible the thought that some objects are independent of all of us, that they would have existed even if there had been no humans (or other sapient creatures), even though, had that been so, there would have been no observation of them or thought about them. (2001, p. 183)

Philosophers certainly do not agree that there are objects independent of our conceptions of the world. ${ }^{4}$ Still, global skepticism is not among the scientifically respectable positions. The substantive dispute that remains between the realist and the constructivist concerns the aboutness of empirical claims and the aboutness of the conceptual models in terms of which they are spelt out (cf. Bickhard 1998). The constructivist maintains that our only warranted claim is that wellcorroborated empirical claims ground out in our models, or abstract constructions that we treat as true for practical reasons. The realist contends that well-corroborated claims ground to properties instantiated in nature, and maintain that such empirical claims track truths about nature. As Kitcher puts it, their dispute "turns on whether determinate relations of reference can exist without metaphysical pointing," and so to gain the upper-hand the realist must establish that empirical claims are not "model-theoretic permutations" by showing that causal connections between ourselves and things in nature fixes our references to them (Kitcher 2001, p. 184).

Realists commonly attempt to establish as much with corroboration arguments, according to which intersubjective validations of empirical claims by independent means, combined with a "no miracles" attitude, is supposed to compel one to favor realism. Many realists also appeal to the fact that our ways of envisaging worldly things are useful for getting around in the world, as evidence that those models are in large part true to model-independent reality; just as a map helping one successfully navigate terrain serves as evidence of its accuracy (Wimsatt 2007, pp. 391-2; cf. Chakravartty 2007, p. 47). Although I too will present a sort of corroboration argument for realism, my overall argument will in certain respects move away from the idea that well-corroborated and useful empirical claims follow from accurate models. This is in the sense that my thought experiment below will establish that the phenomenological content of perceivers, their intrasubjective ways of envisaging things in nature, need not be in accord in order for them to referentially point to and validate the instantiation of the same properties. ${ }^{5}$

\section{Qualia, Qualities, Properties, ANd Inverted-Qualia}

The thought experiment presented in $\$ 4$ is at base a pretty standard "inverted qualia" or "inverted spectrum" experiment (in the vein of Locke 1689 Bk. II, Ch. xxvii and Block \& Fodor 1972). However, in the discussion that follows I will use certain terms that are commonly used when talking about inverted spectrum scenarios in specific and restricted ways. My aim in presenting the experiment is also much different than some well-known appeals to inverted qualia. So, to preempt

\footnotetext{
${ }^{3}$ In response to the van Fraassenian view that empirical models are valued primarily on the basis of their epistemic adequacy, Giere (1988, pp. 193-5) has demonstrated that, in physics at least, scientists demand more of theories than just adequacy.

${ }^{4}$ Active debates in metaphysics regarding the ontological status of emergent "ontic structures" are a testament to this.

${ }^{5}$ It is to be noted that others have recognized that divergent phenomenological content may be irrelevant to intersubjective validations; see, for example, Shoemaker 1975, p. 293-4 and the source cited therein.
} 
misguided interpretations of what I doing in this paper, let me now explain how I will use the relevant terms in this project and make clear what I am not trying to show with my inverted qualia experiment below.

For starters, I will take 'qualia' to be aspects of one's personal phenomenological experience. When we intersubjectively validate something about the world, we are agreeing that a certain kind of personal qualia somehow matches up with someone else's. For example, if you and I were to agree about the color of an emerald green stone, we would be agreeing that we each had emerald green qualia associated with it. I will then take 'qualities' to be the subset of qualia that we experience-as, and talk about as, properties of things in the world (cf. Heil 2003, p. 14). For example, as I will understand qualities in this project, 'emerald green' is the qualia that we may associate with, and attribute as a property of, particular stones (at least pre-reflectively). Embracing this understanding of qualities, as a kind of qualia, enables me to make a distinction between properties of things in the world simpliciter, independent of observation, and properties of things in the world as they are experience phenomenally. Accordingly, I will take 'properties' to be aspects of nature-entities instantiated independent of us.

Many philosophers employ finer-grained distinctions between physical-qualia (e.g. solidity) and mental-qualia (e.g. what it's like to feel sad) and between primary (e.g. spatial extension) and secondary qualities (e.g. smell) (see, for example, Dancy 1985, p. 181). Indeed, distinctions between qualia pertaining to "external" worldly things and "internal" mental things play substantive roles in many historied debates in metaphysics. However, for the purposes of this paper I will not employ such distinctions, and I'll treat all qualia and qualities as if they are on par; in the sense that their trueness or identicality to the non-qualitative properties on which they are claimed to supervene cannot be established (cf. Campbell 1993, pp. 253-4). Accordingly, I will maintain a theory-neutral stance according to which qualities are qualia that we attribute as features of what we perceive and describe or otherwise as individual entities in nature. I adopt this neutral stance on qualities mainly for reasons of economy, as finer distinctions regarding the character of sorts of qualia are simply unnecessary for the purpose of defending realism and the "metaphysical stance."

To be very clear, in this project, I am not concerned with whether some qualia are or are not like properties instantiated out in nature. Because the world appears to be, "hard, cold, colourless, silent, and dead; a world of quantity" independent of our perceptions and models of it, various philosophers argue that qualia are not identical to the functional processes from which they arise (Burt 1932, p. 237). ${ }^{6}$ I do not believe that such non-identicality or identicality can be demonstrated, and I will not speculate about either hypothesis herein. In fact, I am sympathetic to Boltzman's assertion that "we can know but little of the resemblance of our thoughts to the things to which we attach them" (1974, p. 214). Accordingly, I will simply assume that the qualia we attribute as qualities of things in nature are indispensable features of the ways in which we access and ascertain truths about the world "out there," but will commit to little else about the nature of qualia.

Because qualities of macro-objects are so phenomenally distinct from those of their subvenient parts many philosophers have entertained the idea that they are thus robustly existentin the sense of being in an ontological category distinct from their respective subvenient microphysical causes (see Heil 2003, p. 238). As a final clarificatory caveat, it is to be noted that I will also refrain from weighing in on this ontological question in this project. Whether or not qualities would appear in the completed ontology of Laplace's demon, I take it to be uncontentious that entities come to us with qualities as we may encounter or otherwise know them (cf. Williams

\footnotetext{
${ }^{6}$ Even the stalwart materialist Jaegwon Kim advocates this position on the basis that it is metaphysically possible that different qualia may result from the same mechanisms of contact with the same things out in the world; see 2005, pp. $168-7$.
} 
2009, p. 17; Unger 2007, p. 198; Bigelow \& Pargeter 1990; Blackburn 1990, p. 65). This in no way implies that entities qua being exhibit properties that are like our qualia. Nor does it imply that the epistemic gap between our qualia filled visions of phenomena and the nature phenomena independent of us is a narrow one (Cf. Pautz 2006). ${ }^{7}$ Even so, I think it is most plausible that something causes the qualia we attribute as qualities. And I will uphold the realist idea that that something is the causal properties that cause the qualia perceivers like us attribute as qualities when we stand in appropriate perceptual relations to such properties. I will argue moreover that our potentially wildly different qualitatively rich ways of seeing things in the world most plausibly connect at non-qualitative (i.e. categorical and dispositional) properties in the perceiver-independent world, and that such causal properties are the grounds for at least some of our empirical claims. The following thought experiment serves to motivate this realist conclusion.

\section{QUAlia VARIATION WORLD}

I ask you to imagine a possible world, what I will call Qualia Variation World (QVW), in which there are only three beings that are very much like ourselves and experience colors with their eye-like perceptual apparatuses as we do. Imagine further, for the sake of simplicity, that there are only three shades of color that these beings can distinguish in their world (perhaps due to the way that light is reflected or the nature of waves omitted by the sun of QVW). Let's name each of the inhabitants of QVW P1, P2, and P3, and stipulate that the three distinct shades these inhabitants are able to perceive they have named "X," "Y," and "Z." Further, let's say that P1's house is painted all X, P2's all Y, and P3's all Z (as in Figure 1).

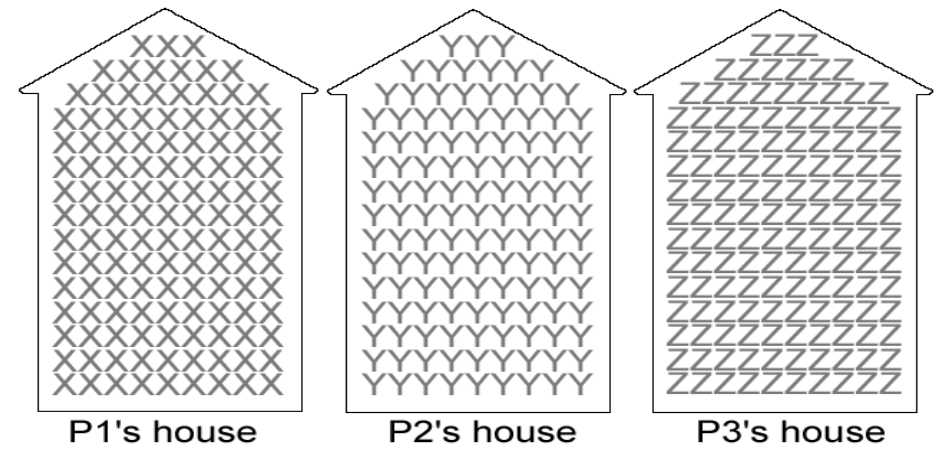

Figure 1

Of course, it is possible that P1, P2, and P3 could agree that each of their houses is a different shade of the three colors that exist in QVW. That is, each could consistently assent to the claims that P1's house is a particular shade of X, P2's a shade of Y, and P3's a shade of Z-just like any three people like you and I might agree about the colors of three different houses. These inhabitants of QVW could also each consistently agree about which other things in QVW are those colors. For example, P1 could have a vehicle that is the same shade of $\mathrm{X}$ as her house. What is interesting is that the inhabitants could agree about all of their references to things being $\mathrm{X}, \mathrm{Y}$, or Z while each having completely different subjective experiences of those colors; that is, different qualia for the same functional relation. For example, P1 and P2 each standing in the 'seeing house as X'

\footnotetext{
${ }^{7}$ It is possible that there are properties like our qualities instantiated in nature, and also possible there are many more qualitative properties than we can even possibly come to experience; cf. Unger 2006, p. 168. It is also possible that properties are multiply natured and may each have dispositional, categorical, and/or qualitative aspects; see Chakravartty 2007, p. 79; Heil 2003, pp. 111; 247.
} 
relation, could each have completely different qualia associated with properties that they agree are $\mathrm{X}$ (as is shown in Figure 2 below). ${ }^{8}$

To expand upon what their situation of invisible disagreement could look like, let's say that P1, 2 , and 3, can only distinguish five shades of what they call "X," "Y," and " $Z$ " (perhaps because of their physiology) and that the following color swatches match up with the three types of subjective experiences of what they call X, Y, and Z that the inhabitants of QVW are capable of having:

\section{A1-5}

\section{B1-5}

\section{C1-5}

Given all of this, it could be that P1's, P2's, and P3's intrasubjective experiences of what they pick out as shades of $\mathrm{X}, \mathrm{Y}$, and $\mathrm{Z}$ are undetectably very different. More specifically, they could each have a drastically different phenonomenal experience of that which they each calls "X," "Y," and "Z," while still agreeing about which things are X, which $\mathrm{Y}$, and which are Z. For instance, each of their intrasubjective experiences of things stably identified as being a shade of $\mathrm{X}$ by every one of the inhabitants could be as follows:

P1 experiences X shades as A1-5 [i.e.

P2 experiences X shades as B1-5 [i.e.

P3 experiences X shades as C1-5 [i.e.
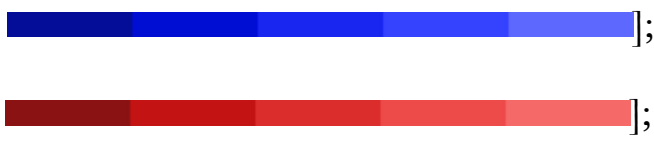

Each of their experiences of things that they agree to be $\mathrm{Y}$ could be:

P1 experiences Y shades as B1-5 [i.e.

P2 experiences Y shades as C1-5 [i.e.

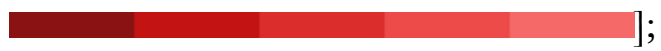

P3 experiences Y shades as A1-5 [i.e.

Finally, each of their experiences of things that they each pick out as Z could be:

P1 experiences Z shades as C1-5 [i.e.

P2 experiences Z shades as A1-5 [i.e.

P3 experiences Z shades as B1-5 [i.e.

Even with this being the case, as long as each of their personal, intrasubjective, experiences of $\mathrm{X}, \mathrm{Y}$, and $\mathrm{Z}$ were always consistent (like all of the things you take to be red always appear red in

\footnotetext{
${ }^{8}$ It is easy to imagine that P1-3 could have distinctive qualia owing to their having different physiological process;
} perhaps due to differences in the structures of their respective eye-like apparatuses. 
the same sort of way), P1, P2, and P3 would be able to communicate about X meaningfully, for instance, without ever being able to detect that they perceive $\mathrm{X}$ very differently — and so on for $\mathrm{Z}$ and Y. More importantly, P1, P2, and P3 would remain able pick out the same properties and other individual entities in nature via their attributions of those thing's qualities, even though their personal experiences of those qualities are unique and disparate.

\section{Tracking Phenomenal Experience or Tracking Truly?}

The question about the above scenario that gets down to the brass tacks of the realist constructivst debate is: What is it that connects each of the QVW inhabitant's subjective experiences such that they are able to come to agreement about what they pick out as $\mathrm{X}, \mathrm{Y}$, and Z? Baring the unlikelihood that they are merely very lucky — and by analogy that we have been miraculously lucky throughout the history of empirical investigation-it is most plausibly whatever causes them to experience $\mathrm{X}, \mathrm{Y}$, and $\mathrm{Z}$ that their subjective experiences converge upon. ${ }^{9}$ The question is then what our evidence demands given that we often reach intersubjective agreement about qualities that we attribute to things in nature. There are two reasonable alternatives.

First, such agreement may be due to intrasubjective experiences being similar. Brian Ellis summarizes this sort of view in saying that, "[ $\mathrm{t}]$ he distinction between red and orange, for example, is a distinction that depends on how we see the world - that is, it depends on our color vision, and does not exist in the world independently of the ways in which we process color information" (2001, p. 102). This could explain our successes in agreeing about colors in this world if our situation is unlike the beings in my QVW scenario. In other words, we might agree about colors because our similar physiologies dictate that we have similar subjective color experiences. However, this answer does not suffice to explain what is going on in QVW, and therefore fails to characterize our own situation if ours' is like that of the inhabitants of QVW to some extent. So, we should entertain a second possible answer to the question of what grounds such agreements.

This is that such agreements about the colors of things in nature ground to causal properties instantiated in nature to which we attribute color qualities. This can explain what is going on in QVW, as it implies the inhabitants intersubjectively validate the occurrence of causal properties operative in bringing about their respective stable qualia experiences A1-5, B1-5, and C1-5. As Sydney Shoemaker explains this realist view: "the relation [between distinct perceivers and the properties to which they map their qualia] holds intersubjectively because the properties involved in the intersubjective case[s] are ones that bestow intrasubjective qualitative similarity when instantiated in the same subject" (2007, p. 125). I must concur with Shoemaker. And this conclusion, and the fact that invisible disagreements can and do occur, bears implications for how to most reasonably formulate realism.

\section{Realists NeEdN'T Commit to Tracking Qualia}

The most mature formulation of realism-what Giere and other philosophers have branded "perspectival realism"-incorporates key elements of constructivism (Giere 2006 and 1999; cf. Chakravartty 2007; Wimsatt 2007). Perspectival realists, as realists, maintain that causal connections between properties instantiated in nature and ourselves ground our references to those properties, while at once conceding to the constructivist that our conceptions of properties instantiated in nature are perspective relative_-or filtered through our theoretical and perceptual perspectives. I

\footnotetext{
${ }^{9}$ Searle (1995, Ch. 8) argues that we must assume that external realism is true to communicate. My suggestion is that the fact that we can communicate about the objects of perception and intersubjectively correct for errors in our empirical models is compelling evidence that we detect and model the world at least partially correctly.
} 
submit that this basic formulation of realism, as perspectival realism, is right. Yet, I submit that the possibility (and occurrence) of invisible disagreements shows that certain further claims of perspectival realists are problematic, and that the view must be formulated in a carefully restricted way.

Particularly problematic is some perspectival realist's presumption that our subjective perceptions are the same, as this goes beyond what the realist has evidence for claiming. In fact, Giere himself engages this idea (if somewhat implicitly) in the course of examining color vision experiments that show that our stable subjective color vision (e.g. seeing a certain shade of 'yellow') can be caused by different stimuli. Giere points to these experiments to show that what he calls "objective realism" does not seem to accommodate how we experience color. He explains that objectivist realism is the view that empirical claims present a "literally true story of what the world is like" (van Frassen 1980, p. 8). He rebuffs this view, arguing that we are only warranted in asserting that our empirical claims approximate to objective truths through the lens of our instruments, perceptual faculties, and models - that is, mitigated and distorted by our theoretical and perceptual perspectives. He says that we are therefore warranted only in the claim that the world is "roughly such and such" from a well-validated perspective, and that "objective realism" is too simplistic (2006, p. 6). Though I agree with this, I take issue with Giere's implication that sharing a perspective on properties in nature requires having similar subjective experiences of those properties. A closer look at the color experiments just mentioned and the phenomenon of 'metamerism' serves to make clearer why this is.

As Giere explains, 'metamerism' is:

$[\mathrm{P}]$ roductions of the same color experience by light with different spectral characteristics. For example, monochromatic light with a wavelength around $580 \mathrm{~nm}$ projected on a neutral screen will be experienced as pure yellow [...] The same color experience, however, can be produced by an appropriate intensity mixture of two monochromatic lights with wavelengths of $540 \mathrm{~nm}$ (a greenish yellow) and 640nm (a redish yellow). (2006, p. 21)

He submits that this result shows that color is real, but perspectival. Although this seems right upon first inspection, a more careful look shows that one cannot explain what is going on in QVW if one buys into the idea that color is real only from a perspective. Furthermore, because it is possible that our situation is like the inhabitants of QVW, and most plausible that our situation mirrors theirs to a certain extent, it therefore comes to light that Giere's claim to the perspectival reality of color-i.e. the isomorphism of a color to a functional perspective-is problematic.

The crucial thing the QVW scenario highlights is that similarity of phenomenological content is unnecessary for intersubjective agreement about some way the world actually is. Thus, intersubjective agreement may be achieved not because of similarities in how we each receive the world but because what we access out in nature somehow causes stable intrasubjective qualia when typical (e.g. sighted and non-hallucinating) perceivers like us stand in similar relations to those things out in the world. I submit moreover that the perspectival realist must embrace this conclusion to maintain a coherent position. This is because for perspectival realism to be a species of realism, and avoid collapsing into variation of constructivism, it must demand more than that empirical claims are true in virtue of grounding to a perspective or accurately describing what is perspectivally real.

Realists must make Kitcher's demand that empirical claims are grounded in what he calls the "really real." This is to say that good empirical claims must be about things that are "independent not just of each but of all of us"; that is, independent of any sapient beings beliefs, references to them, or observations (Kitcher 2001, p. 155; cf. Bunge 1973, p. 145). If the inhabitants of QVW agree about how they each track colors, the most plausible explanation is then that what they track 
with what they pick out as $\mathrm{X}, \mathrm{Y}, \mathrm{Z}$ are the properties out in the world that cause their respective subjective phenomenological content. They do not validate their subjective perceptual content nor that they intersubjectively agree about their subjective experiences of $\mathrm{X}, \mathrm{Y}$, and Z, as is Giere's position if we take him seriously when he says that colors are perspectivally real.

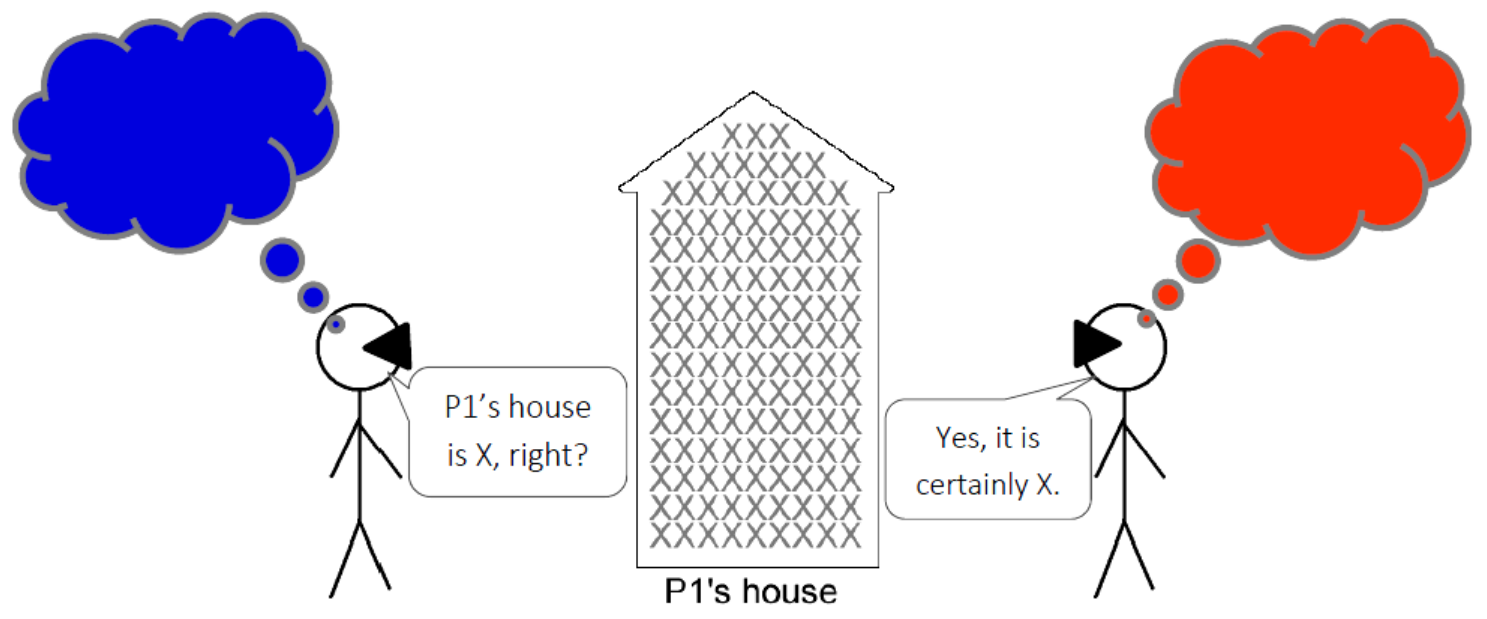

Figure 2

Giere is correct that, "[w]ithout perceivers like us, there would be no experiences of color" in the sense that there would not be color vision (1999, p. 80). However, this does not imply that colors are merely perspectivally real. What it implies is that the properties to which we attribute color qualities are not necessarily in fact how we perceive them. What is real, and what grounds our empirical claims, is not perspective relative in the sense that it is real only from a perspective. Rather, how we detect the real and the interfacing formats (e.g. languages and models) we use to corroborate our detections are perspectival. Still, what we intersubjectively validate is what properties are out in nature that we detect (as is illustrated in Figure 2). This does not require that we detect what is out there the same way, even if by similar perceptual apparatuses (e.g. our eyes). Indeed, it is because we validate the "out there" from different partial perspectives that we are able to recognize that color properties are not always, and I think most probably not ever, the way we perceive them.

We know that cats lack the perceptual machinery to receive wavelengths of light in color, and that some insects are apparently able to receive ultraviolet wavelengths that we cannot percieve. We know that individual people can see the same color properties differently, and it is simply the case that we may each have very different experiences of qualities-not unlike the inhabitants of QVW. This all just goes to show that subjective experiences of things in the world are perspective relative, which teaches us nothing new. Yet, recognizing that none of this perspective relative variation prevents us from identifying color properties lends credence to a realist theory of color according to which what we see is wavelengths of light reflected by properties instantiated in nature.

Empirical claims about colors are at base about properties instantiated in nature. Accordingly, in the case of color, what we intersubjectively validate are not claims about what we see but claims about what properties are instantiated out in nature. In terms of the received account of color as resulting from only some wavelengths of light being reflected by the surfaces of objects, what is being validated are claims about the "spectral reflectance" of certain surfaces (Byrne \& Hilbert 2003, pp. 8-9). In other words, we are saying that certain surfaces are textured, or have patterned microphysical shapes, such that they produce some specific qualitative experience when we stand in appropriate perceptual relations to those surfaces. If this is all right, as I am suggesting, 
then perspectival realism should not entail that colors are real but perspectival. Rather, perspectival realism should have it that colors are reflectant properties, textures, that are interpreted differently from different perspectives.

\section{CONCLUSION}

One cannot deny that our world is to some extent like QVW-especially since advances in neurobiology continue to reveal more and more that it is. It is even very unlikely that we each have subjective qualia experiences that are exactly alike each other's, given the brute fact of physiological variability and the many contingent factors that may impact how we perceive things (cf. Dennett 1988). Indeed, one can easily alter his or her own qualia experiences simply by putting on "inversion goggles," ingesting halucinagens, or starring at the sun for too long. More to the point, upon some reflection I think the claim that we each have unique phenomenal experiences of the qualities of things about which we agree is rather uncontroversial. For example, I think it is most probably true that the very same \#0064 blue color swatch looks somewhat different to each of us. Hence, we are most probably like the inhabitants of QVW in that we have many invisible disagreements even though we are in strong intersubjective agreement about the qualities that we "invisibly disagree" about.

In the QVW scenario, the most reasonable, explanation for the inhabitants' intersubjective agreement is that specific properties and property-types out in the world cause each of their respective perceptions of color qualia. And it is at least highly plausible that those properties, what colors really are, are spectrally reflectant texture properties. In my interpretation, the inhabitants of QVW, P1-3, intersubjectively corroborate that they have access to the same properties in nature by standing in causal relations to those things so as to receive and physiologically process what they perceive as color qualities. ${ }^{10}$ They therefore have access to the "really real" in that there is a causal pathway tracing backward from effects (the qualities in their perceptions) to causes (reflectant properties). Hence, their empirical claims regarding colors ground to their pointing to the same color causing properties of the same objects - whatever those properties are like independent of their perceptions and models of reality. ${ }^{11}$ Accordingly, we must conclude that the grounds of at least some of our empirical claims are properties instantiated in nature. The constructivist can only dogmatically allege that this realist claim goes beyond what our evidence demands and is more than we need as good empiricists. However, in light of the above considerations of invisible disagreements about color, this basic realist claim appears to be exactly what we need to make sense of our successes in agreeing about ways the world is.

Acknowledgements I am grateful to the Philosophy \& Humanities Department at SUNY Buffalo State for giving me the opportunity to try out the arguments in this paper at the Fall 2015 Faculty Colloquia. I would also like to thank Amanda Hicks for commenting on a very early version of this work.

\footnotetext{
${ }^{10}$ Interestingly this is compatible with the fact that perceived qualities do not always match up to what would be considered their regular causes. For example, in certain, irregular, circumstances we can perceive different colors than those that regularly correspond to the wavelengths received by the eye. For instance, observing green color patches and then white or gray color patches can elicit experiencing the latter as green; see Campbell 1993, pp. 253-6. Alternative examples include common cases of color blindness; see Heil 2003, pp. 201-2.

${ }^{11}$ Some argue that properties of objects are similar only if they bring about the same qualities in their possessors; see Heil 2003, p. 145 and Giere 2006, p. 14. In my view, the same properties can sometimes cause different qualia, and I leave open the possibility that some qualities may just be qualia that do not supervene on any other properties; cf. Campbell 1993, pp. 256-8.
} 


\section{Works Cited}

Bickhard, Mark H. (1998). Levels of representationality. Journal of Experimental \& Theoretical Artificial Intelligence, 10(2), 179-215.

Bigelow, J., \& Pargetter, R. (1990). Science and necessity: Cambridge Univ Pr.

Blackburn, Simon. (1990). Filling in Space. Analysis, 50(2), 62-65.

Block, N.J., \& Fodor, J.A. (1972). What psychological states are not. The Philosophical Review, 81(2), 159-181.

Boltzmann, L. (1974). Theoretical physics and philosophical problems: selected writings: Springer.

Bradley, M. (2011). The Causal Efficacy of Qualia. Journal of Consciousness Studies, 18, 11(12), 32-44.

Bunge, MA. (1973). Method, Model, and Matter. Dordrecht: D. Reidel Pub. Co.

Burtt, E.A. (1932). The metaphysical foundations of modern science: Dover.

Byrne, Alex, \& Hilbert, David R. (2003). Color realism redux. Behavioral and Brain Sciences, 26(01), 52-59.

Campbell, K. (1993). David Armstrong and Realism about Colour. In J. Bacon, K. Campbell \& L. Reinhardt (Eds.), Ontology Causality and Mind, Essays in Honor of DM Armstrong (pp. 249-268): Cambridge University Press.

Chakravartty, A. (2007). A metaphysics for scientific realism: knowing the unobservable: Cambridge Univ Pr.

Dancy, Jonathan. (1985). An Introduction to Contemporary Epistemology: B. Blackwell.

Dennett, DC. (1988). Quining Qualia. In A. Marcel \& E. Bisiach (Eds.), Consciousness in Contemporary Science: Oxford, Oxford University Press.

Ellis, B.D. (2001). Scientific essentialism: Cambridge Univ Pr.

Giere, RN. (2006). Scientific Perspectivism: University of Chicago Press.

Giere, R.N. (1988). Explaining science: A cognitive approach: University of Chicago Press.

Giere, R.N. (1999). Science without laws: University of Chicago Press.

Hawking, Stephen. (2011). The grand design: Random House LLC.

Heil, J. (2003). From an ontological point of view: Clarendon Press.

Kim, J. (2005). Physicalism, or something near enough: Princeton University Press.

Kitcher, P. (2001). Real realism: the Galilean strategy. The Pbilosophical Review, 110(2), 151-197.

Noë, A. (2004). Action in perception: the MIT Press.

Pautz, A. (2006). Can the physicalist explain colour structure in terms of colour experience? Australasian Journal of Philosophy, 84(4), 535-564.

Pettit, P. (2003). Looks as powers. Philosophical Issues, 13(1), 221-252.

Psillos, Stathis. (2013). Semirealism or Neo-Aristotelianism? Erkenntnis, 78(1), 29-38.

Robertson, L.C., \& Sagiv, N. (2004). Synesthesia: Perspectives from cognitive neuroscience: Oxford University Press, USA.

Searle, J.R. (1995). The construction of social reality: The Free Press.

Shoemaker, Sydney. (1975). Functionalism and Qualia. Philosophical Studies: An International Journal for Philosophy in the Analytic Tradition, 27(5), 291-315.

Shoemaker, Sydney. (2007). Physical Realization: Oxford University Press.

Sider, T. (2012). Writing the Book of the World: Oxford University Press.

Sober, E. (2008). Empiricism. The Routledge Companion to the Philosophy of Science, 129-138.

Unger, P. (2007). All the Power in the World: Oxford University Press, USA.

Van Fraassen, B.C. (1980). The scientific image: Oxford University Press, USA.

Van Fraassen, B.C. (1989). Laws and symmetry: Oxford University Press, USA.

Van Fraassen, B.C. (2002). The empirical stance: Yale Univ Pr.

Ward, D., Roberts, T., \& Clark, A. (2011). Knowing what we can do: actions, intentions, and the construction of phenomenal experience. Synthese, 181(3), 375-394.

Williams, Neil Edward. (2009). The ungrounded argument is unfounded: A response to Mumford. Synthese, 170(1), 7-19.

Wimsatt, William C. (2007). Re-Engineering Philosophy for Limited Beings: Piecewise Approximations to Reality: Harvard University Press. 